\title{
Ação-formação: uma leitura das contribuições da Ergonomia da Atividade
}

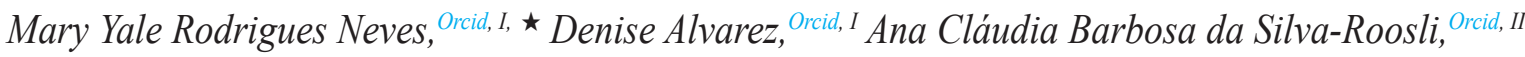

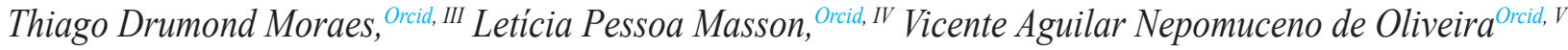 \\ ${ }^{I}$ Universidade Federal Fluminense, Niterói, RJ, Brasil / II Universidade Estadual de Londrina, Londrina, Paraná, PR, Brasil \\ ${ }^{I I I}$ Universidade Federal do Espirito Santo, Vitória, ES, Brasil / ${ }^{I V}$ Fundação Oswaldo Cruz, Rio de Janeiro, RJ, Brasil \\ ${ }^{V}$ Universidade Federal do Estado do Rio de Janeiro, Rio de Janeiro, RJ, Brasil

\begin{abstract}
Resumo
Este artigo objetiva refletir acerca das interações entre formação e ação ergonômica, especificamente, na perspectiva da Ergonomia da Atividade. Seu ponto de partida é a trajetória histórica dessa interface, sinalizando dilemas e alternativas pautadas nas relações entre análise do trabalho e ações formativas. Seus desdobramentos são explorados a partir do "paradigma da formação de atores na e pela análise do trabalho, para e pela ação", ancorado na interdependência entre formação e transformação das condições de trabalho. Conclui-se que este paradigma abre novas vias de análise sobre a sustentabilidade da ação ergonômica e sobre a luta pela saúde.
\end{abstract}

Palavras-chave: Ergonomia e formação; psicologia e ergonomia; pesquisa-ação-formação; análise do trabalho.

\section{Action-training: a reading of the contributions of the Activity Ergonomics}

\section{Abstract}

This article aims to reflect on the interaction between training and ergonomics' action, specifically, from the Activitycentered Ergonomics perspective. Its starting point is the historical trajectory of this interface, signaling dilemmas and alternatives based on work analysis and training programs relations. Its developments are explored from the "paradigm of training in and by the analysis of work, to and by action", anchored in the interdependence between training and working conditions transformation. It is concluded that this paradigm opens new avenues of analysis on the sustainability of the ergonomics' action and on the struggle for health.

Keywords: Ergonomics and training; psychology and ergonomics; research-action-training; work analysis.

\section{Introdução}

Este artigo tem como objetivo refletir acerca das interações entre formação e ação ergonômica, especificamente na perspectiva da Ergonomia da Atividade $^{1}$ (DANIELLOU, 2004; FALZON, 2007, 2016; TEIGER; LACOMBLEZ, 2013; WISNER, 1994), além de explorar seus desdobramentos a partir do "paradigma da formação dos atores na e pela análise do trabalho, para e pela ação" (LACOMBLEZ; TEIGER, 2007; LACOMBLEZ; TEIGER; VASCONCELOS, 2014; LACOMBLEZ; VASCONCELOS, 2009; TEIGER; LACOMBLEZ, 2005, 2006).

Tem-se como ponto de partida o projeto da Ergonomia em compreender o trabalho a fim de encontrar encaminhamentos possíveis para a sua transformação (GUÉRIN et al., 2012), cujo horizonte é articular a saúde e segurança dos trabalhadores com a eficácia e qualidade no/do trabalho. Esta aposta na transformação das situações reais de trabalho manifesta um esforço em distanciar-se de modelos de intervenção orientados para a mudança de comportamentos dos trabalhadores, alheios à conquista da saúde e que não consideram o ponto de vista da atividade acerca da eficácia no trabalho e na construção e definição do que seria saudável.

\footnotetext{
^Endereço para correspondência: Universidade Federal Fluminense, Instituto de Psicologia, Campus do Gragoatá. Rua Professor Marcos Waldemar de Freitas Reis, $\mathrm{s} / \mathrm{n}^{\mathrm{o}}$, Bloco N, $4^{\circ}$ andar. São Domingos - Niterói, RJ - Brasil. CEP: 24210-201.E-mail: myale@uol.com.br, alvarez.dena@gmail.com, acbs79@gmail.com, thiago.moraes@ufes.br, leticiapessoa@yahoo.com.br Sempre que fizermos referência à Ergonomia neste texto, referimo-nos à Ergonomia da Atividade, de origem francófona, e posteriormente lusófona, mesmo que o termo "atividade" não apareça na expressão.
}

A perspectiva que orienta o projeto da Ergonomia é a da adaptação do trabalho ao homem (FAVERGE; LEPLAT; GUIGUET, 1958) - e não a de adaptação do homem ao trabalho, conforme apregoado pelo padrão taylorista/fordista de organização do trabalho -, o que levou à prevalência da transformação do trabalho e de suas condições sobre a (trans)formação dos indivíduos. Nesta direção, Lacomblez e Teiger (2007) apontam para um dilema histórico enfrentado pelos pioneiros da Ergonomia: agir sobre as condições de produção ou sobre os indivíduos? Lacomblez, Teiger e Vasconcelos (2014, p. 159) argumentam, no entanto, que este é um falso problema, pois não é possível concretizar um sem o outro, ou seja, "os dois aspectos - o desenvolvimento das pessoas em curso de formação e a ação sobre os elementos da situação - são, apesar de tudo, indissociáveis".

É no cerne deste debate que emergiu, portanto, certo interesse no que diz respeito às potencialidades de uma intervenção formativa, que passa a ser entendida como "uma alavanca para a ação, uma passagem útil para uma difusão mais alargada do projeto da ergonomia" (LACOMBLEZ; VASCONCELOS, 2009, p. 54). Subjacente a este interesse está também o reconhecimento de que a melhoria das condições de trabalho não dependeria exclusivamente dos conhecimentos científicos e técnicos daqueles que conduzem a intervenção. Em vez disto, exigiria fundamentalmente a participação dos protagonistas do trabalho envolvidos no processo, questão que contribuiu para a abertura de uma nova via de abordagens, em que se destaca a proposição mais recentemente denominada de "paradigma da formação 
de atores na e pela análise do trabalho, para e pela ação" (LACOMBLEZ; TEIGER, 2007; LACOMBLEZ; TEIGER; VASCONCELOS, 2014).

A formação passa, então, a ser vista como instrumento de desenvolvimento e transformação para a ação. O que é diferente da visão de forma-t-ação vigente em grande parte dos programas de formação profissional (LACOMBLEZ; TEIGER; VASCONCELOS, 2014), em que se colocam os trabalhadores frequentemente como "receptores" de informações e conhecimentos técnicos e científicos.

Conforme apresentamos a seguir, será descrita inicialmente a trajetória da interface entre Ergonomia e formação. ${ }^{2}$ Posteriormente, identificaremos alguns dos princípios e bases conceituais, bem como as articulações teóricas que situam de modo mais preciso as relações entre a perspectiva da formação de atores, que se encontra ainda em consolidação no Brasil, e a contribuição para a ampliação e o fortalecimento da capacidade normativa dos trabalhadores. Entendemos que esta última dimensão é imprescindível para a transformação das situações de trabalho no sentido da conquista da saúde.

\section{A emergência da relação Ergonomia e formação: as articulações entre análise do trabalho e ações formativas}

Nos mundos do trabalho, no período do segundo pós-guerra, apresentam-se exigências de modernização e produtividade tidas como necessárias em função do esforço de reconstrução dos países europeus. O desafio era o de selecionar e formar o maior número possível de trabalhadores para as indústrias de produção em grande escala, elevando ao máximo a eficácia e reduzindo o tempo e o custo ao mínimo possível (DANIELLOU, 2004; LACOMBLEZ; TEIGER, 2007; TEIGER; LACOMBLEZ, 2005).

Nesse contexto, conforme sinalizam Teiger e Lacomblez (2005), configurou-se uma demanda por formação, cujos principais temas dos programas realizados remetiam à organização do trabalho - pautada pelos princípios tayloristas/fordistas -, à prevenção de acidentes e segurança no trabalho e ao desenvolvimento profissional. Tal demanda levou à criação de organismos voltados para o estudo da fisiologia humana, que tiveram um papel destacado no desenvolvimento da Ergonomia.

O interesse pela formação profissional de adultos, no âmbito da análise ergonômica do trabalho, situa-se, desse modo, desde os anos 1950, a partir dos trabalhos de Faverge (DELGOULET; VIDAL-GOMEL, 2016; FALZON; TEIGER, 2001; VIDAL, 2003; WISNER, 1994, 2004). De acordo com Teiger e Lacomblez (2005), os primeiros manuais francofônicos já sinalizavam para a elaboração de algumas noções e definição de conteúdos de base, tais como: análise do trabalho (OMBREDANE; FAVERGE, 1955), aporte da análise do trabalho em formação (LEPLAT, 1955) e adaptação da máquina ao homem (FAVERGE; LEPLAT; GUIGUET, 1958).

\footnotetext{
Também encontrada em diversas outras contribuições (BERTHELETTE; LACOMBLEZ; TEIGER, 1998; LACOMBLEZ; TEIGER; VASCONCELOS, 2014 LACOMBLEZ; VASCONCELOS, 2009; TEIGER; LACOMBLEZ, 2005, 2006).
}

A obra de Ombredane e Faverge de 1955, intitulada L'analyse du travail: facteur d'economie humane et de productivité, possuía um capítulo dedicado a problemas de formação profissional. Nele se colocava em relevo um julgamento favorável acerca do método destinado, em especial, a valorização do papel do contramestre - tido como um elemento estratégico para organizar e transmitir conhecimentos -, e os princípios de elaboração de uma ação de formação. Já os trabalhos pioneiros de Leplat (1955 apud TEIGER; LACOMBLEZ, 2005, p. 12) apontavam para os limites da formação calcada apenas nos estudos tayloristas dos tempos e movimentos das tarefas.

Pode-se afirmar, então, que a aproximação entre ergonomistas pioneiros e o campo da formação deu-se gradualmente, ancorada na preocupação em ultrapassar uma tendência clássica caracterizada pelo diagnóstico e recomendação e na necessidade de colaborar com ações de transformação das condições de trabalho baseadas em abordagens participativas, bem como na intenção de contribuir com a sustentabilidade das ações (DELGOULET; VIDAL-GOMEL, 2016), questão intrínseca ao paradigma fundador da Ergonomia (DANIELLOU, 2004; LACOMBLEZ; VASCONCELOS, 2009; WISNER, 2004).

Deve-se ter em conta que, principalmente a partir dos anos 1970, as organizações sindicais eram as principais representantes da 'demanda social' à época (DANIELLOU, 2004; LAVILLE, 1977; WISNER, 1994). A partir da experiência dos sindicatos e do Laboratório de Fisiologia do Trabalho do Conservatoire National des Arts et Métiers (CNAM) na França, apostava-se que a formação na metodologia da análise ergonômica do trabalho(AET) permitiria a constituição de uma ferramenta para a ação dos trabalhadores, além da instauração de um diálogo continuado entre pesquisadores e sindicalistas (LACOMBLEZ; TEIGER; VASCONCELOS, 2014). Essas experiências, que conciliam Ergonomia e ações formativas, expandiram-se posteriormente para além dos sindicatos, com o uso desta metodologia com atores de empresas (COSTA; SILVA, 2010; LACOMBLEZ; VASCONCELOS, 2009; PETIT, 2008).

Conforme Vasconcelos (2008), o engajamento nas modalidades formativas que se desenvolveram a partir daí exige a reflexão em torno de três tipos de conhecimentos: relacionados aos modelos teóricos da atividade e da relação entre saúde e trabalho; sobre os métodos de análise do trabalho; e sobre as condições de ação em organizações, e não somente no posto de trabalho. Balizada por estes conteúdos, a análise do trabalho nas intervenções formativas assume diferentes funções, conforme apresentamos a seguir.

\section{Conexões possíveis entre análise do trabalho e formação}

Marcada pela diversidade e dinamicidade, a trajetória da relação entre Ergonomia e ações de formação, tradicionalmente, engloba dois direcionamentos: um que adota a análise do trabalho como objeto de formação e 
outro que transforma a intervenção ergonômica em uma ação de formação, justificada e definida a partir da análise do trabalho (LACOMBLEZ; TEIGER, 2007).

No primeiro direcionamento, trata-se da "formação em análise do trabalho" de trabalhadores implicados na concepção do trabalho e/ou em ações de saúde e segurança. Ora objetiva-se formá-los em análise do trabalho (via transmissão dos modelos teóricos da atividade), ora a formação pode acompanhar uma intervenção ergonômica numa ação de cooperação entre formandos e ergonomistas na transformação do trabalho.

A formação em análise do trabalho constitui-se uma maneira de facilitar a passagem da formação para a ação, ao possibilitar que trabalhadores com diferentes vinculações institucionais na organização modifiquem suas representações acerca do trabalho.

Champy-Remoussenard (2005) registra, a partir da década de 1970, a emergência de abordagens de formação baseadas em uma análise preliminar do trabalho, conferindo outro estatuto para a análise do trabalho em conexão com programas de formação. Circunscreve-se aí mais claramente o segundo direcionamento dado à relação entre Ergonomia e ações de formação: a "análise do trabalho como preliminar ao projeto de formação".

Este movimento alimenta-se também do aumento da demanda das empresas europeias/francesas por formação nas décadas de 1980 e 1990, fruto das mudanças no trabalho que passaram a exigir mais flexibilidade, polivalência e capacidade de lidar com eventos inesperados por parte dos trabalhadores, cuja ênfase desloca-se da qualificação para as competências (SCHWARTZ, 2010).

Assim, a aposta na 'análise do trabalho preliminar à formação’ dá-se pela oportunidade de acesso aos saberes convocados pelos trabalhadores, diferenciando-os dos saberes acadêmicos. Tal posicionamento é parcialmente congruente à noção de competências que, para Schwartz (1998, 2010), trata-se mais de um "agir em competência" em uma situação, do que o domínio de saberes ou modos de se comportar previamente incorporados. ${ }^{3}$ Esse encaminhamento permite o afastamento de uma concepção de transmissão de conhecimentos gerais, teóricos, padronizados e supostamente generalizáveis para uma diversidade de situações, bem como um afastamento de representações predefinidas acerca dos conhecimentos que os trabalhadores necessitariam. Além dos delegados sindicais ou profissionais da concepção, principais destinatários do primeiro direcionamento das formações para análise do trabalho, os programas de formação passam a se destinar também aos demais trabalhadores das empresas. É nesta perspectiva que o domínio da formação profissional que privilegia o ponto de vista da atividade tem se alimentado, constituindo

\footnotetext{
Este "agir em competência" refere-se menos a um conjunto de saberes e modos de se comportar e ser e mais a uma composição de diferentes "ingredientes" cujas relações dinâmicas entre si nunca são verdadeiramente antecipáveis e que se compõem de pelos menos três elementos, como enumera Schwartz (1998, p. 101): "O grau de apropriação de saberes conceitualizáveis, o grau de apreensão das dimensões propriamente históricas da situação e o debate de valores a que se vê convocado todo indivíduo num meio de trabalho particular".
}

uma diversidade de projetos, entre os quais se destacam aqueles realizados notadamente em Portugal e em países francofônicos (TEIGER; LACOMBLEZ, 2013).

Para efeito deste texto, privilegiar-se-á a seguir uma incursão no "paradigma da formação de atores na e pela análise do trabalho, para e pela ação", proposição conciliadora em relação aos dois direcionamentos acima citados, ancorada na interdependência entre formação e transformação das formas de organização e condições de trabalho.

\section{Por um novo paradigma de produção de conhecimento e intervenção: a sinergia entre pesquisa-formação-ação}

Pode-se situar como um dos disparadores da perspectiva de formação, que a pensa articulada à pesquisa e à ação voltadas aos mundos do trabalho, o método proposto por Teiger e Laville (1991) para a formação com sindicalistas na França, tendo se difundido posteriormente por vários países, como o Brasil. Tal método era pautado pela autoanálise do trabalho, onde a avaliação ergonômica seria realizada pelo próprio operador envolvido com a situação real de trabalho. Nessa direção, as experiências de formação com os sindicatos possibilitaram intervir no trabalho, mesmo nos casos em que não havia acesso autorizado pelas empresas, revelando-se uma maneira de assessorar os sindicatos em suas lutas pela formação dos seus quadros. Ademais, tais experiências contribuíram para transformações do/ no trabalho, inscrevendo-se numa tradição de diálogo entre pesquisadores do trabalho e organizações sindicais (TEIGER; LAVILLE; DURAFFOURG, 2004).

Paralelo a esse processo, na Itália, Oddone, Re e Briante (1981) experimentam o desenvolvimento de um novo paradigma de formação, estreitamente associado à pesquisa, por meio da proposta da constituição de uma "comunidade científica ampliada" (CCA), na qual pesquisadores e sindicalistas irão "formar-se", com um propósito comum de potencializar o raio de ação para transformar o trabalho (LACOMBLEZ; TEIGER, 2007; LACOMBLEZ; TEIGER; VASCONCELOS, 2014; MUNIZ et al., 2013).

Assim, um novo paradigma de pesquisa se coloca progressivamente, ao associar pesquisa e formação recíproca de pesquisadores e sindicalistas. Entendese, então, que o formador precisa estar atento para estabelecer uma relação de mediação com os atores neste percurso. Tal papel assumido pelo formador revela-se de enorme importância em todas as etapas da intervenção, trabalhando sempre em dois planos: a) o do desenvolvimento individual, intrinsecamente ligado à explicitação e formalização do saber-fazer; b) e o do reconhecimento social ao nível da empresa, a fim de manter o sentido e o alcance da experiência. De acordo com as referidas autoras para atender a esses dois planos o formador precisa ser experiente em análise ergonômica, revelando uma postura que seja simultaneamente, do tipo clínica (atenta às dinâmicas da palavra dos atores sobre

Fractal, Rev. Psicol., v. 30 - n. 2, p. 112-120, 2018 
o trabalho) e do tipo estratégica (considera a pertinência dos atores nesta experiência social que é a intervenção) (LACOMBLEZ; TIGER, 2007, p. 598).

Trata-se de projetos que visam afirmar um espaço de intervenção que concede centralidade à dimensão participativa, apostando no diálogo e confrontação entre os conhecimentos dos especialistas e os conhecimentos dos trabalhadores como capaz de gerar outros processos de mudança, bem como de ampliar as possibilidades de ação destes últimos em seus próprios contextos de trabalho.

Nas intervenções, favorecem-se então dispositivos de participação das diversas categorias de atores que se constituem em espaços de aprendizagem recíproca, mesmo que a formação não seja em si o foco da intervenção. Entretanto, é preciso cuidado, alertam-nos Lacomblez e Teiger (2007), pois, por trás da noção de participação, há muitas maneiras de atuar: algumas intervenções favorecem apenas a constituição de pequenos espaços de restituição, enquanto outras envolvem o conjunto de atores em todas as etapas da análise e transformação das situações de trabalho, entre as quais o paradigma de formação que é objeto do presente artigo.

A autoanálise do trabalho contribui para o desenvolvimento de competências do trabalhador acerca da análise e formulação de propostas alternativas para a situação vivida por ele. Nessas práticas, também é fundamental cuidar das condições de acompanhamento das transformações esperadas, para não colocar os trabalhadores numa "situação isolada e desarmada perante obstáculos técnicos ou organizacionais que ultrapassam suas capacidades de ação" (LACOMBLEZ; TEIGER, 2007, p. 593). As autoras chamam a atenção continuamente para a armadilha de se realizar uma formação em Ergonomia, com qualquer um dos atores, sem se criar condições para que eles possam atuar e participar da transformação, já que essa possibilidade não é um desdobramento automático do processo de formação e é preciso pensá-la com cautela, na perspectiva de fortalecer a dimensão coletiva da formação-ação e sua necessária multiplicação.

\subsection{O "paradigma da formação de atores na e pela análise do trabalho, para e pela ação": alguns princípios e bases conceituais}

Tendo como base alguns dos princípios elencados anteriormente por Lacomblez, Teiger e Vasconcelos (2014), pode-se pensar em pontos norteadores para a transformação dos sistemas de produção de modo compatível com a saúde e a segurança dos trabalhadores. Dentre eles, destacam-se: o reconhecimento da especificidade dos saberes da experiência de cada um, a necessidade de criação de condições que garantam tanto a comunicação quanto o confronto de saberes e a importância da atividade de reflexão no processo que conduz à ação.

Para operacionalizá-los, ressalta-se a importância da criação de dispositivos de participação que abarquem as diversas categorias de trabalhadores das organizações, assim como a progressiva instalação de uma dinâmica de circulação linguageira que possibilite não só o compartilhamento de uma linguagem comum sobre a atividade estudada, como também a possibilidade da emergência de controvérsias, que é uma ferramenta "desenvolvimental" importante. Essa construção, em conjunto com as observações do trabalho em curso e validações, permitirá a formalização e apropriação de múltiplas "regras para a ação".

Outro aspecto, de igual importância e que se associa às duas características presentes na formação (seu caráter clínico e sua dimensão estratégica), é o caráter de aprendizagem mútua experimentada em práticas de intervenção que associavam formação, pesquisa e intervenção. A formação se anuncia então como uma prática de mudança, uma construção progressiva e desenvolvimental de "lugares mais comuns" e, portanto, do agir e da ação, ou seja, de uma reconfiguração dos cenários de intervenção formativa nos locais de trabalho (LACOMBLEZ; TEIGER; VASCONCELOS, 2014; LACOMBLEZ; VASCONCELOS, 2009). Apesar do "desconforto intelectual" (SCHWARTZ, 1995) que pode suscitar - ao se ter os saberes disciplinares testados e validados(ounão)no decorrer da realidade sempremutante das atividades -, a vigilância ética e metodológica faz parte integrante desse projeto e serve como uma espécie de "fio condutor" para salvaguardar um quadro analítico onde o desenvolvimento dos saberes profissionais nunca é dissociado da sua relação com os riscos para a saúde física e mental. Há, então, a necessidade de se instruir sobre as atividades de trabalho, seus recursos, suas potencialidades e suas reservas de alternativas (SCHWARTZ; ABDERRAHMAN; ADRIANO, 2008). Para Lacomblez e Vasconcelos (2009), a intenção é a de contaminar os espaços de trabalho e de pesquisa com um certo modelo de humanidade que nos faça ver o nosso semelhante, seja ele operador ou decisor, como alguém que está "em atividade", isto é, alguém cuja atividade é lugar de gestão de debates de normas atravessado por um mundo de valores, lugar de resingularização permanente da situação (SCHWARTZ; DURRIVE, 2010).

O encaminhamento assinalado acima se apoia, portanto, na premissa que o processo de compreensão do trabalho visa à sua transformação, assim como a do trabalhador. Assim, consoante aos fundamentos da Ergonomia da Atividade, está presente aí a ideia de que aprender a analisar o trabalho permite ao trabalhador refletir sobre a realidade de sua atividade e tornar-se mais confiante para envolver-se em uma ação. Nessa perspectiva, a relação entre pensamento e ação é pensada a partir de uma dupla tradição: da "filosofia da ação e da pedagogia construtivista” (TEIGER; MONTREUIL, 1996).

A "filosofia da ação" enfatiza em particular a ação de mudança, entendida como uma abertura para o projeto e concepção de outras possibilidades, que começa no momento em que nos tornamos capazes de conceber "outro estado das coisas". Alguns autores (COUTAREL et al., 2009; PETIT, 2008; TEIGER; MONTREUIL, 1996) buscam em Sartre uma referência para este debate. Para o filósofo, a ação não resulta de um processo de sofrimento profundo que tornaria insustentável uma situação, mas, ao 
contrário, resulta da percepção de que esse "outro estado" é possível e que, somente dessa forma, se poderia dar-se conta deque a situação é sofrida e insustentável.

Para Teiger e Montreiul (1996), o interesse particular da Ergonomia pelas mudanças no trabalho faz com que a concepção de "outro estado das coisas" seja o objeto da formação em discussão. Dessa forma, é "o aspecto dinâmico da transformação das representações de uma situação que proporciona o impulso para mudar os pontos de vista, permitindo, assim, ações que transformam situações" (TEIGER; MONTREUIL, 1996, p. 87). Nesse caso, a ação é entendida num sentido lato, já que o essencial é debater as representações iniciais acerca do trabalho, da saúde e da prevenção de acidentes e doenças, que são frequentemente redutoras, e transformá-las em representações para ação, fornecendo bases de análise das situações e enriquecendo a argumentação para as mudanças (LACOMBLEZ; TEIGER, 2007).

A noção de representação é bastante polêmica, pois alguns campos de conhecimento atribuem-lhe um caráter predominantemente cognitivista, alinhado ao positivismo. Em Ergonomia, esse conceito relaciona-se à outra tradição. ${ }^{4}$ Conforme Lacomblez e Teiger (2007), as representações seriam mediadores entre cognição e ação, motores potenciais de uma ação de mudança da situação. Wisner (2004) relaciona o uso da noção de representação na Ergonomia francófona a uma das correntes da análise do trabalho (DE KEYSER, 1991; LEPLAT, 1996), que afirma a possibilidade da análise da atividade levar a explorar uma camada subjacente à cognição, denominada de representação.

Segundo essa corrente, a representação, também denominada por Weil Fassina, Rabardel e Dubois (1993), como "representação para a ação", pode ser muito diferente de operador para operador. Pode também ser fortemente coerente ou assemelhar-se mais a uma espécie de "mosaico". As representações se construiriam progressivamente, à medida que se desenvolvessem os cursos da ação e não se limitariam às dimensões materiais da tarefa, podendo ser construídas também em relação às pessoas com as quais se relacionam em seu meio de trabalho. Esse aspecto lhes configuraria uma espécie de pano de fundo das comunicações, trocas, acordos, sinergias que se darão nos diferentes cursos da ação. Segundo os autores, tal noção de representação tornou-se importante para a tentativa de compreensão do que se passa na atividade.

Para a "pedagogia construtivista", o conhecimento não consiste apenas na capacidade de copiar o real, mas de agir sobre ele e transformá-lo. A aprendizagem resultaria da associação entre conhecimento e ação, não considerando um como cópia ou aplicação do outro, mas sim como a capacidade de agir sobre o real, transformando-o "em" e "pela" ação. A influência de tal orientação teórica na perspectiva de formação em foco revela-se pela atenção à criação de dispositivos de participação

\footnotetext{
${ }^{4}$ Para uma discussão mais aprofundada acerca da noção de representação na Ergonomia, remetemos o leitor para o artigo intitulado "Revisitar a noção de representação em Ergonomia”, de Marianne Lacomblez, nesse Dossier.
}

de diversas categorias de trabalhadores engajadas tanto na análise das situações que emergem, quanto na formalização e apropriação de múltiplas alternativas para a ação. Distancia-se, portanto, da compreensão de que o aprendizado em análise do trabalho ocorreria por meio de uma formação que ensine a memorizar as suas etapas. Neste sentido, tratar-se-ia da realização de uma "formação 'oportuna', procurando, na medida em que se desenrola, provocar uma atividade reflexiva pela confrontação das representações e dos conhecimentos trazidos por todos" (LACOMBLEZ et al., 2016, p. 124).

Tais conhecimentos não são previamente determinados em um plano de formação. Para isso, é essencial refletir sobre a metodologia da formação, seus momentos e fases. As diferentes experiências, voltadas para agir tanto nas condições de trabalho, quanto na formação dos trabalhadores, organizam os momentos e fases da pesquisa-ação-formação à sua maneira. Apesar da diversidade, podem ser identificadas quatro etapas principais. A "expressão espontânea", quando os trabalhadores expressam nos primeiros diálogos as representações iniciais que possuem sobre seu trabalho. A "expressão provocada", sustentada por um questionamento de tipo maiêutico, quando o ergonomistaformador faz emergir "o que nem sempre se sabe que se sabe", a complexidade e variabilidade do trabalho, as "competências desconhecidas", os compromissos assumidos entre a produção e a segurança. Nessa etapa, pode-se gerar no participante um sentimento de que esta percepção é só sua. Torna-se necessário então, garantir na formação um "processo de objetivação-distanciamento" que permita desindividualizar a interpretação das consequências do trabalho e abrir caminhos para a ação coletiva. Em seguida, criam-se condições para que os participantes assumam o "protagonismo no quadro do exercício coletivo", quando o grupo de formandos deve se apropriar das formas de compreender e transformar o trabalho por meio de exercícios práticos (LACOMBLEZ; TEIGER; VASCONCELOS, 2014).

Para tanto, afirma-se a necessidade de não só se constituir um "espaço público" para a discussão sobre a atividade (DEJOURS, 2012), mas também de articularemse diretamente os resultados daí provenientes às questões de promoção de saúde.

\section{Ação ergonômica, promoção da saúde e segurança no trabalho e sua relação com as questões de formação}

É importante sinalizar que a perspectiva de formação aqui apresentada e privilegiada é convergente, a nosso ver, com a linhagem que compreende saúde como criação e recriação de normas (CANGUILHEM, 2005), característica humana presente em qualquer situação de vida. Portanto, no contexto das atividades de trabalho, a luta pela saúde também se expressa pela atenção à capacidade normativa dos próprios trabalhadores mobilizada na transformação das condições de realização de seu trabalho, e seu fortalecimento. Assim, entendemos que há uma relação indissociável entre luta pela saúde, ação ergonômica e intervenção formativa; não apenas 
com o intuito de contribuir para a prevenção de acidentes e doenças, mas, principalmente, em um sentido mais amplo, o que se refere à saúde como potência para lidar com a existência (CZERESNIA, 2013).

Deve-se chamar a atenção, entretanto, para que, ainda que tal relação seja indissociável, não foi senão muito recentemente que ela encontrou um terreno propício em dispositivos de formação que permitissem desenvolvê-la em sua maior potencialidade. Neste sentido, Lacomblez et al. (2016) ressaltam que a análise da atividade de trabalho e suas ligações com a saúde, além de permitir a construção de novos conhecimentos, no sentido amplo, propiciam um processo de tomada de consciência individual e coletiva, que deveria permitir a elaboração de 'um outro possível' no dia a dia de trabalho.

Outro aspecto a ressaltar no que tange à relação entre saúde, segurança e formação é que, para alguns autores (LACOMBLEZ; TEIGER, 2007; VASCONCELOS, R.; LACOMBLEZ, 2004), o ponto de partida para construir um dispositivo de formação em/pela análise do trabalho para/pela ação capaz de superar a dicotomia transformação dos trabalhadores/do trabalho, se sustenta exatamente sobre a análise dos "saberes-fazer de prudência" (CRU; DEJOURS, 1987). Esses saberes, como expressão da criação de normas pelos trabalhadores são, de todo modo, indissociáveis dos saberes-fazer profissionais e mobilizam fortemente sua inteligência prática (DEJOURS, 2012).

Tais saberes-fazer de prudência são fundamentais para a constituição de condutas real e eficazmente seguras, embora, segundo Cru e Dejours (1987), submetidos à ideologia defensiva, ${ }^{5}$ esses saberes não são vividos nem descritos espontaneamente como tais pelos trabalhadores. Dejours (1995) destaca que estes saberes não são ensinados nem durante a formação dos operários, nem pela supervisão, mas são considerados (juntamente com os demais saberes-fazer) "artifícios do oficio", transmitidos de geração a geração pela coletividade operária, sendo peças-chave não apenas para a manutenção da segurança, mas também para a otimização do processo produtivo, auxiliando na conquista/manutenção da saúde dos operadores (CRU; DEJOURS, 1987).

Neste sentido, os autores relacionam experiência e um certo saber-fazer sobre a saúde e a segurança que levam um tempo (não estritamente cronológico) para serem conquistados e estabilizados junto a um ofício ou uma profissão, como as estratégias para se evitar lombalgias, dores e acidentes, incorporadas na experiência profissional e nas profissões. Assim, ao se considerar a saúde como capacidade normativa (CANGUILHEM, 2005), os saberes de prudência - e seu desenvolvimento via formação que os incorpore - podem ser vistos

\footnotetext{
${ }^{5}$ As estratégias de defesa correspondem aos sistemas defensivos formulados estrategicamente e coletivamente pelos próprios trabalhadores e que funcionam como regras compartilhadas para lutar contra aquilo que os faz sofrer. Estes sistemas conduzem à modificação, transformação e, muitas vezes, à eufemização da percepção das contradições presentes na situação de trabalho. Expressam a inserção ativa dos trabalhadores. Por outro lado, quando a manutenção da defesa torna-se por si só o objetivo dos trabalhadores, estas estratégias convertem-se em ideologia e perdem sua capacidade propositiva de transformações efetivas na realidade do trabalho (DEJOURS, 2012)
}

como elementos importantes na conquista da recriação cotidiana das normas e, portanto, de transformações efetivas nos mundos do trabalho.

Dessa forma, entende-se que as estratégias de defesa e os saberes-fazer de prudência devem ser parte da formação ergonômica (TEIGER; LACOMBLEZ, 2006). A integração desses elementos à formação corresponde, pelo menos, a duas contribuições: tanto à reflexão sobre as estratégias de prevenção, aprimorando-as e indo no sentido de uma transformação mais efetiva dos riscos, a partir da ampliação da capacidade normativa dos trabalhadores; quanto para o desenvolvimento profissional dos coletivos de trabalho envolvidos na formação, que poderão dialogar sobre suas regras de ofício, mantendo-se em um movimento dinâmico de autocrítica e desenvolvimento, sem se estagnarem.

Vasconcelos e Lacomblez (2004) ressaltam ainda que, para que os saberes-fazer de prudência possam ser imbricados no processo de construção de uma prevenção real e verdadeiramente eficaz, é essencial buscar sua ascensão, conscientização, contextualização e compreensão. Os autores defendem essa ideia mesmo reconhecendo a dificuldade de verbalização e acesso às chamadas "competências incorporadas". Indispensável a um trabalho seguro e de qualidade, a sabedoria do corpo, segundo eles, deve ser integrada junto com os conhecimentos formalizados em "atividades reflexivas - no trabalho, sobre o trabalho, pelo trabalho e para o trabalho" (LACOMBLEZ; TEIGER; VASCONCELOS, 2014, p. 168).

Deve-se lembrar, ainda, a tradição do Modelo Operário Italiano de luta pela saúde (ODDONE et al., 1981), que se mantém muito atual e instrumental ao afirmar que nenhum conhecimento especializado externo aos coletivos de trabalho pode decretar quais seriam os riscos aceitáveis (VOGEL, 2016). Não se trata, segundo Vogel (2016), de repetir nostalgicamente o que se passou na experiência dos anos 1960 e 1970, mas, não desconsiderando alguns de seus limites, pensar sobre a radicalidade desta experiência e as possibilidades de reativá-la em condições significativamente diferentes (MUNIZ et al., 2013; SCHWARTZ, 2000).

Nessa perspectiva de formação, deve-se partir dos riscos profissionais, mas ultrapassando-os, para se produzir outro olhar sobre a atividade, tendo como instrumento a análise da atividade. Visa-se assim ao desenvolvimento profissional dos trabalhadores e, ao mesmo tempo, a instauração ou ampliação de um olhar crítico sobre as situações de trabalho quer sobre seus aspectos técnicos e organizacionais, quer sobre as questões relacionadas à segurança e à saúde no trabalho (LACOMBLEZ; TEIGER, 2007).

Neste sentido e também no bojo desta perspectiva, Silva et al. (2009), indo de encontro a proposições estandartizadas, ressaltam a importância da construção de uma promoção da saúde que remete à apreensão, por parte de trabalhadores e pesquisadores profissionais, do real das situações de trabalho, compreendido em sua relação com o processo saúde-doença. Para tanto, 
os autores designam esse processo de "promoção da saúde a 'partir' das situações de trabalho" (PSST), com o propósito de, tendo como ponto de partida os locais de trabalho, monitorar as formas de organização e condições de trabalho para agir, simultaneamente, de forma preventiva e propositiva nas fontes potencialmente nocivas à saúde, afirmando e validando as formas de luta eventualmente já em curso.

Pensamos que privilegiar tal perspectiva de formação, atravessada pelo projeto da Ergonomia (que busca conciliar critérios de eficácia e qualidade, saúde e segurança), colabora para a abertura de um diálogo com os modos predominantes de se pensar a formação (frequentemente denominados sob a rubrica de Treinamento \& Desenvolvimento), especialmente presente em determinada vertente da Psicologia Organizacional e do Trabalho. (BORGESANDRADE; ABBAD; MOURÃO, 2006). Ao explicitar a indissociabilidade entre o desenvolvimento de competências em situação, transformação do trabalho e conquista da saúde, possibilita-se a abertura de novos encaminhamentos para as estratégias de formação de trabalhadores, notadamente direcionados para $\mathrm{o}$ fortalecimento de sua capacidade normativa. Assim, uma intervenção formativa potencializaria o engajamento na luta pela saúde e afirmação da vida, mesmo que tal questão não tenha sido formalmente formulada em demandas iniciais.

\section{Considerações finais}

Ao adotarmos como ponto de reflexão a relação entre formação e Ergonomia da Atividade, visamos nos beneficiar de algumas das contribuições desta última para a elaboração de ações formativas, entendendo-as como mais uma via para a expansão das possibilidades de transformação das situações de trabalho que contemplem e afirmem a saúde dos trabalhadores.

Diante do desafio de superar a visão de "forma-t-ação", vigente principalmente em grande parte dos programas de formação profissional, e as dificuldades em garantir a sustentabilidade da ação ergonômica, as propostas de articulação entre formação e ação ergonômica destacam-se como um patrimônio importante para o desenvolvimento de abordagens, como o "paradigma de formação de atores na e pela análise do trabalho, para e pela ação", conforme apresentado.

A partir de novos diálogos conceituais, notadamente inscritos nas contribuições da Ergonomia da Atividade, esse paradigma favorece o alargamento da discussão em torno da questão da participação dos trabalhadores em intervenções que almejam a (trans)formação do/no trabalho e a conquista da saúde.

O reconhecimento do protagonismo dos trabalhadores e sua capacidade de produção de saberes se coloca como um posicionamento ético e epistemológico, o que implica por conduzir os "formadores" a um lugar menos central nos dispositivos de formação, apresentando-se mais como mediadores e mobilizadores de análises do que como "transmissores" de conhecimento. Como vimos, tem-se esta como uma questão chave, já que tal perspectiva de formação compreende o trabalhador como um sujeito competente, ativo e reflexivo, detentor de um ponto de vista, de um projeto e de uma especialização própria adquirida pela experiência individual e coletiva.

A ênfase recai, portanto, na exigência de a formação criar oportunidades para o desenvolvimento e debate dessas competências entre trabalhadores de diferentes categorias profissionais e formadores, num processo de coaprendizagem que pode conduzir de forma mais ampla à transformação da compreensão acerca do trabalho, irrigando diferentes relações e diferentes projetos de ação sobre as formas de organização e condições de trabalho.

Por fim, adotarmos o olhar atento e situado acerca da atividade de trabalho, a partir da interlocução com aqueles que protagonizam tais situações é considerar que o trabalho, assim como a vida, apresenta-se em constante mutação e que esse deve ser o fio condutor para orientar ações de formação, pesquisa e intervenção.

\section{Referências}

BeRTHeletTE, D.; LACOMBLEZ, M.; TEIGER, C. La conception de programmes de formation à et par l'analyse du travail: réflexions sur des travaux en cours em ergonomie, psychologie du travail et en recherche évaluative. Deuxièmes Journées Recherche et Ergonomie. Toulouse: Université Toulouse le Mirail, 1998. p. 123-130.

BORGES-ANDRADE, J. E.; ABBAD, G. S.; MOURÃO, L. (Org.). Treinamento, desenvolvimento e educação em organizações e trabalho: fundamentos para a gestão de pessoas. Porto Alegre: Artmed, 2006.

CANGUILHEM, G. (Org.). A saúde: conceito vulgar e questão filosófica. In: Escritos sobre a medicina. Rio de Janeiro: Forense Universitária, 2005. p. 35-48.

CHAMPY-REMOUSSENARD, P. Les théories de l'activité entre travail et formation. Savoirs, v. 2, n. 8, p. 9-50, 2005.

COSTA, C.; SILVA, C. Análise do trabalho, formação contextualizada e acção de transformação das condições de trabalho no sector de saneamento de um serviço municipal. Laboreal, v. 6, n. 2, p. 27-46, 2010.

COUTAREL, F. et al. Orientações para a avaliação das intervenções visando a prevenção dos problemas músculoesqueléticos ligados ao trabalho. Laboreal, v. 5, n. 2, p. 95-108, 2009.

CRU, D.; DEJOURS, C. Saberes de prudência nas profissões da construção civil: nova contribuição da Psicologia do Trabalho à análise da prevenção de acidentes na construção civil. Revista Brasileira de Saúde Ocupacional, v. 15, n. 59, p. 30-34, 1987.

CZERESNIA, D. Os sentidos da saúde e da doença. Rio de Janeiro: Fiocruz, 2013.

DANIELLOU, F. (Org.). Introdução: questões epistemológicas acerca da Ergonomia. In: A Ergonomia em busca de seus princípios: debates epistemológicos. São Paulo: Edgard Blucher, 2004. p. 1-18.

DE KEYSER, V. Works analysis in French language ergonomics: origins and current research trends. Ergonomics, v. 34, n. 6, p. 653-669, 1991.

Fractal, Rev. Psicol., v. 30 - n. 2, p. 112-120, 2018 
DEJOURS, C. Inteligência operária e organização do trabalho: a propósito do modelo japonês de produção. In: HIRATA, H. (Org.). Sobre o 'modelo' japonês. São Paulo: EdUSP, 1995. p. 281-309.

DEJOURS, C. Trabalho vivo. Brasília: Paralelo 15, 2012.

DELGOULET, C.; VIDAL-GOMEL, C. O desenvolvimento das competências: uma condição para a construção da saúde e do desempenho no trabalho. In: FALZON, P. (Org.). Ergonomia construtiva. São Paulo: Blucher, 2016. p. 35-54.

FALZON, P. (Org.). Ergonomia. São Paulo: Edgar Blucher, 2007.

FALZON, P. (Org.). Ergonomia construtiva. São Paulo: Bluchered, 2016.

FALZON, P.; TEIGER, C. Ergonomia e formação. In: CARRÉ, P.; CASPAR, P. (Org.). Tratado das ciências e das técnicas da formação. Lisboa: Piaget, 2001. p.161-178.

FAVERGE, J.-M.; LEPLAT, J.; GUIGUET, B. L'adaptacion de la machine à l'homme. Paris: PUF, 1958.

GUÉRIN, F. et al. Compreender o trabalho para transformá-lo: a prática da ergonomia. São Paulo: Edgar Blücher, 2012.

LACOMBLEZ, M. et al. Marianne Lacomblez e a construção de uma Psicologia da Atividade de Trabalho. Cadernos de Psicologia Social do Trabalho, v. 19, n. 1, p. 121-133, 2016.

LACOMBLEZ, M.; TEIGER, C. Ergonomia, formações e transformações. In: FALZON, P. (Org.). Ergonomia. São Paulo: Blucher, 2007. p. 587-601.

LACOMBLEZ, M.; TEIGER, C.; VASCONCELOS, R. A Ergonomia e o "paradigma da formação dos atores": uma parceria formadora com os protagonistas do trabalho. In: BENDASSOLLI, P. F.; SOBOLL, L. A. P. (Org.). Métodos de pesquisa e intervenção em Psicologia do trabalho: clínicas do trabalho. São Paulo: Atlas, 2014. p.159-183.

LACOMBLEZ, M.; VASCONCELOS, R. Análise ergonómica da actividade, formação e transformação do trabalho: opções para um desenvolvimento durável. Laboreal, v. 5, n. 1, p. 5360, 2009.

\section{LAVILLE, A. Ergonomia. São Paulo: EPU, 1977.}

LEPLAT, J. Analyse du travail et formation. Bulletin $d u$ CERP, v. 4, n. 4, p. 393-409, 1955.

LEPLAT, J. Quelques aspects de la complexité en ergonomie. In: DANIELLOU, F. (Org.). L'ergonomie en quête de ses príncipes. Toulouse: Octarès, 1996. p. 57-76.

MUNIZ, H. et al. Ivar Oddone e a sua contribuição para o campo da Saúde do Trabalhador no Brasil. Revista Brasileira de Saúde Ocupacional, v. 38, n. 128, p. 280-291, 2013.

ODDONE, I.; RE, A.; BRIANTE, G. Redécouvrir l'expérience ouvrière: vers une autre psychologie du travail? Paris: Messidor/ Éditions Sociales, 1981

OMBREDANE, A.; FAVERGE, J. L'analyse du travail: facteur d'économie humaine et de productivité. Paris: PUF, 1955.

PETIT, J. A intervenção ergonômica como dinâmica de aprendizagem: estudo de caso. Laboreal, v. 4, n. 2, p. 37-46, 2008.

SCHWARTZ, Y. De l'inconfort intellectuel, ou: comment penser les activités humaines? In: COURS-SALIES, P. (Org.) La liberté du travail. Paris: Syllepse, 1995. p. 99-149.
SCHWARTZ, Y. Os ingredientes da competência: um exercício necessário para uma questão insolúvel. Educação \& Sociedade, v. 19, n. 65 , p. 101-140, 1998.

SCHWARTZ, Y. A comunidade científica ampliada e o regime de produção de saberes. Trabalho e Educação, n. 7, p. 38-46, jul/dez 2000

SCHWARTZ, Y. Anexo ao capítulo 7. Uso de si e competência: exposição de Yves Schwartz e comentários sobre os esquemas 5, 6 e 7. In: SCHWARTZ, Y.; DURRIVE, L. (Org.). Trabalho \& ergologia: conversas sobre a atividade humana. Niterói: EdUFF, 2010. p. 205-221.

SCHWARTZ, Y.; ABDERRAHMAN, F.; ADRIANO, R. Revisitar a actividade humana para colocar as questões do desenvolvimento: projecto de uma sinergia franco-lusófona. Laboreal, v. 4, n. 1, p. 10-22, 2008.

SCHWARTZ, Y.; DURRIVE, L. (Org.). Trabalho e ergologia: conversas sobre a atividade humana. Niterói: EdUFF, 2010.

SILVA, E. et al. A promoção da saúde a partir das situações de trabalho: considerações referenciadas em uma experiência com trabalhadores de escolas públicas. Interface (Botucatu), v. 13, n. 30, p. 107-119, 2009.

TEIGER, C.; LACOMBLEZ, M. L'ergonomie et la transformation du travail et/ou des personnes (1). Education Permanente, v. 165, p. 9-28, 2005.

TEIGER, C.; LACOMBLEZ, M. L'ergonomie et la transformation du travail et/ou des personnes (2). Education Permanente, v. 166, p. 9-28, 2006.

TEIGER, C.; LACOMBLEZ, M. (Org.). (Se) Former pour transformer le travail: dynamiques de constructions d'une analyse critique du travail. Laval: Presses de l'Université Laval, 2013. p. 764. Collection Santé et sécurité du travailed.

TEIGER, C.; LAVILLE, A. L'apprentissage de l'analyse ergonomique du travail, outil d'une formation pour l'action. Travail et emploi, v. 1, n. 47, p. 53-62, 1991.

TEIGER, C.; LAVILLE, A.; DURAFFOURG, J. Trinta anos depois: reflexão sobre uma história das relações entre pesquisa em ergonomia e ação sindical na França (o caso das operárias do setor eletrônico entre 1965 e 1975). In: FIGUEIREDO, M. et al. (Org.). Labirintos do trabalho: interrogações e olhares sobre o trabalho vivo. Rio de Janeiro: DP\&A, 2004. p. 135-160.

TEIGER, C.; MONTREUIL, S. The foundations and contributions of ergonomic work analysis in training programmes. Safety Science, v. 23, n. 213, p. 81-95, 1996.

VASCONCELOS, R. O papel do psicólogo do trabalho e a tripolaridade dinâmica dos processos de transformação: contributo para a promoção da segurança e saúde no trabalho. 2008. Tese (Doutorado)-Faculdade de Psicologia e de Ciências da Educação, Universidade do Porto, Porto, 2008.

VASCONCELOS, R.; LACOMBLEZ, M. Entre a auto-análise do trabalho e o trabalho de auto-análise: desenvolvimento para a psicologia do trabalho a partir da promoção da segurança e saúde no trabalho. In: FIGUEIREDO, M., et al. (Org.). Labirintos do trabalho. Rio de Janeiro: DP\&A, 2004. p.161187.

VIDAL, M. Guia para análise ergonômica do trabalho (AET) na empresa: uma metodologia realista, ordenada e sistemática. Rio de Janeiro: EVC, 2003. 
VOGEL, L. A atualidade do modelo operário italiano nas lutas pela saúde no trabalho. Laboreal, v. 12, n. 2, p. 10-17, 2016.

WEILL-FASSINA, A.; RABARDEL, P.; DUBOIS, D. (Org.). Représentations pour l'action. Toulouse: Octarès, 1993.

WISNER, A. A inteligência no trabalho: textos selecionados de ergonomia. São Paulo: Fundacentro, 1994.

WISNER, A. Questões epistemológicas em Ergonomia e em análise do trabalho. In: DANIELLOU, F. (Org.). A Ergonomia em busca de seus princípios: debates epistemológicos. São Paulo: Edgar Blücher, 2004. p. 29-56.

Recebido em: 3 de junho de 2017

Aceito em: 23 de janeiro de 2018 